\title{
Vernacular Memorialisation in the Military: Personal Acts of Remembrance at RAF Thorpe Abbotts.
}

\author{
In September 2017, an archaeological excavation at RAF Thorpe Abbotts \\ uncovered 7 identification 'dog' tags belonging to airmen of the United States \\ Army Air Force (USAAF). It is the thesis of this article that these were \\ purposefully buried by individuals within the 100th Bomb Group (Heavy) as acts \\ of remembrance. Alongside the dog tags were a number of other artefacts, \\ including coins, bottles and a canteen cup. These likely formed the material \\ culture of self-developed grieving rituals established by the primary group \\ responsible for the deposition of the dog tags.
}

Keywords: Second World War; remembrance; memorialisation; United States Army Air Force.

\section{Introduction}

During times of war, troops serving in combat zones are faced with the ever present threat of death or injury. Despite individual's developing coping strategies, this fear will have an inevitable psychological impact. In addition, soldiers have to emotionally deal with the loss of comrades. During the First and Second World Wars, it was unsurprising that civilians, finding themselves in uniform, suffered when exposed to total war (Saunders 2009, 42). The development of grieving rites and acts of remembrance can aid this process. Whilst deployed, soldiers live, work, and socialise together. In these settings, units develop a level of 'intimacy' that provides their major source of support (Tyler and Gifford 1991, 235). The sudden, and often violent, loss of a member of the primary group would have a significant impact on the unit (Durham 1996, 1-2). In this article, the response of one primary group to the death of their comrades will be examined. Through personal grieving rituals and acts of remembrance, the individuals developed ways to deal with loss. 
Archaeologists are increasingly interested in the material culture of war (e.g., Barnes 2018; Carr 2018; Carr and Mytum 2012; Joy 2002; Myers 2008; Rydén 2018; Saunders 2009). The archaeological study on the remembrance of conflict, however, has mainly focused on post-conflict memory (e.g., Black 2004; Carr 2012; Keating 2012; Moshenska 2006; Moshenska 2009; Pollard, 2015; Renshaw 2016; Stephens 2007; Stone 2004; Tarlow 1997; Trigg 2007). Grieving rites of combatants during times of war, and its associated material culture, has also been understudied. This article, therefore, will present evidence for a site of vernacular memorialisation developed by members of the 100th Bomb Group (Heavy) during a time of war.

In 1948, Stafford-Clark, in his study on 'Morale and Flying Experience', recorded the attitude of aircrews of RAF Bomber Command towards the death of a comrade. During his interviews, he noticed that the men generally expressed a sense of 'supreme realism'. There was very little evidence of the aircrews demonstrating any 'outspoken expression[s] of their feelings, nor did they display any compromise with conventional reticence about the fact of violent death' (Stafford-Clark 1948, 15). Instead:

\footnotetext{
"They said "Too bad ... sorry about old so-and-so ... rotten luck"; their regret was deep and sincere, but not much displayed or long endured. They were apt and able to talk of dead and missing friends, before mentioning their fate, just as they talked of anyone else or of themselves. It took the loss of particular friends or leaders ... to produce a marked reaction among a squadron. They might feel collectively distressed, have a few drinks because of that, go on a party and feel better. But they made no effort to escape the reality of the situation, nor was there any of the drinking to forget referred to in accounts of flying in the last war' (Stafford-Clark 1948, 15).
}

In order to deal with the emotional stresses associated with the threat of death and injury, soldiers develop a shell of 'indifference' (Holmes 2004, 203). During the 
Second World War, soldiers were 'young; they were resilient; they lived until they died' (Stafford-Clark 1948, 15). Archaeological evidence from RAF Thorpe Abbotts, home to the 100th Bomb Group throughout the war, however, suggests that members of this primary group developed grieving rites to cope with loss (Fig. 1).

In September 2017 and March 2018, archaeological excavations were conducted at RAF Thorpe Abbotts as part of a wider project run by the University of East Anglia. This work was supported by the Centre of East Anglian Studies, the 100th Bomb Group Memorial Museum, the American Veterans Archaeological Recovery Program, Norvic Archaeology, and Waveney Valley Community Archaeology Group. The aim of the fieldwork was to discover more about everyday life of the GIs of the 100th Bomb Group who were based at RAF Thorpe Abbotts for 3 years from June 1943. Colloquially referred to as the 'Bloody Hundredth', this unit gained a notorious reputation for sustaining high casualties (Freeman 1997, vi). There was a common held belief within other groups that no one ever 'finished from the Bloody Hundredth!' (Nilsson 1946, prologue).

During the excavations of the site in September 2017, the project team uncovered a vernacular memorial. This site was a focus of personal acts of remembrance and self-developed grieving rituals. In this article, the burial of dog tags, 'toasting' of the dead, and the deposition of objects will be presented as ways individuals of the 100th Bomb Group dealt with loss.

\section{Archaeological Findings}

As part of the fieldwork at RAF Thorpe Abbotts in September 2017, a metal detecting survey was conducted of Communal Site No. 1. Commonly used in conflict archaeology (e.g., Balicki 2011; Cornelison 2000; Ferguson 2013; Pollard 2009; Pollard 2011), this technique, when used on military facilities, can reveal 'patterns that provide 
insight into the variations in use of different areas of the camps and the behaviour of their occupants' (Barnes 2018, 172).

During this survey, an identification tag, more commonly known as a 'dog' tag, was discovered buried in the earthen bank of the static water tank (Fig. 2). With the uncovering of a second tag in close proximity to the first, the decision was taken to open a trench. In total, 7 dog tags were excavated from a $2.2 \mathrm{~m}$ by $3 \mathrm{~m}$ trench alongside a number of other artefacts (Fig. 3): 5 of the dog tags were recovered from context 1001 and 2 from 1002.

Following the processing of the dog tags during the post-excavation phase of the project, it was determined that they belonged to 6 individuals from the 100th Bomb Group (Fig. 4): Sgt Max Newman (d. 26 November 1943) (Registered Find (RF) 5), Lt Marvin Leininger (d. 30 December 1943) (RF16), S/Sgt Nicholas Matulik (d. 30 December 1943) (RF5) and S/Sgt Donald Becker (d. 3 March 1944 both of Becker's dog tags were found) (RF9 and RF12) were all killed in action (KIA) and were all part of the 349th Bomb Squadron. The other 2 tags belonged to Lt Jack Bauman, S-2 Intelligence (RF10), and Cpl Karl Treanor, armourer in 418th Bomb Squadron (RF11), who both survived the war, but have now passed away. Within the trench there were also 13 coins (12 British and 1 American), and a canteen cup associated with 2 drinks bottles, possibly for beer. The cup and bottles were excavated in the same assemblage as Newman's and Matulik's dog tags (RF5). Within the immediate vicinity of the trench, a 0.5 cal casing (RF13) and 2 American '13 star' buttons (RF19) were uncovered. Besides from the dog tags, only $2.503 \mathrm{~kg}$ of artefacts were recovered from the trench (context 1000 contained 479g of metal and 1463g of glass, 1001 contained $464 \mathrm{~g}$ of metal and 1002 contained a single halfpenny). It is believed that the uncovering 
of multiple non-faulty dog tags from a single location outside of a combat zone is unique.

\section{Site Interpretation}

Before this site can be interpreted as a site of vernacular memorialisation, it is important to examine other explanations for how the dog tags ended up besides the static water tank. The simplest explanation is the carelessness of the soldiers. However, if these were random losses, one would expect to find a haphazard distribution of tags across the site. During the March 2018 excavations of RAF Thorpe Abbott's Accommodation Site No. 1, 4 dog tags were uncovered by the metal detecting survey. Unlike the 7 from Communal Site No. 1, these were not clustered in a single location, but randomly scattered across the site. There was also no evidence of the chains that they were attached to in the trench. Veterans working on the excavations reported that it is a modern practice to place a tag in their shoes during deployment. This ensures that there is a means of identification at both ends of the body. It is possible that GIs also did this during the Second World War. Tags kept in shoes might have been lost more easily.

In a daily bulletin of the 389th Bomb Group dated 27 October 1944, it was reported that a 'considerable number of delinquency reports are being received on personnel of this station for not having identification tags or for not wearing them properly. All personnel going on leave, pass or furlough must have either dog tags in their possession and will be instructed to wear them on a suitable cord or chain around their necks' (2nd Air Division Memorial Library Microfilm B01418 (Hethel), 2072, 27 October 1944 author's emphasis). Not wearing their dog tags properly supports the hypothesis that they were not always on a chain around their necks. The clustering of tags within this small space might be explained if it was a high footfall area. However, a steep ditch bordered the site on one side and the static water tank on the other. 
During the war, it is possible that the GIs used the static water tank as a swimming pool. The dog tags could then have been lost while the 6 men were changing. These tags, however, were essential components of a soldier's kit: they were important to identify the bodies of those killed in combat (Sledge 2005, 100, 103). In the War Department's Technical Manual (TM) 10-630: Graves Registration, 23 September 1941, it gave clear instructions that tags should be 'habitually kept in the possession of the owner' (as quoted in Sledge 2005, 103). One veteran of the 100th Bomb Group, Lt John 'Jack' Furrer, reported that they 'wore our dog tags all the time in case you were wounded ... or dead' (personal communication, October 4, 2017). If these dog tags were lost, then the owners would have made every effort to locate them. The random loss of 7 tags within the same small area is an exceptional coincidence.

Evidence of high footfall beside the static water tank is not visible in the archaeological record. The ditch at the base of the bank, which the Trustees of the 100th Bomb Group Memorial Museum believe has never been dredged, was almost absent of finds. If GIs were regularly conglomerating besides the static water tank, one would expect to find buttons, badges, bottles and other similar material culture. There is no evidence that this site was either a high footfall area or a popular site for off-duty socialising. Besides the dog tags, the only other concentration of artefacts in the trench were some coins (12 British and 1 American). Across the rest of Communal Site No. 1, only 4 additional coins were uncovered by the metal detecting survey. The concentration of dog tags and coins besides the static water tank, combined with the absence of other material culture, indicates these artefacts were purposefully deposited, not lost.

Of the 7 dog tags, 5 (RF05, RF09, RF10, and RF11) were excavated from the top of the earthen bank built up against the static water tank. It was determined that 
these artefacts were deposited between $80 \mathrm{~mm}$ and $300 \mathrm{~mm}$ beneath the Second World War ground surface. This is indicative of the fact that the dog tags had been purposefully buried at this location. If they had been lost, one would expect to find them in the base of the ditch where they had been washed by runoff. The archaeological evidence clearly demonstrates that the dog tags and other artefacts recovered from the trench were deliberately buried or left at this location.

To determine why the dog tags might have been buried, it is important to gather further information about the GIs who were originally issued with the tags. The 4 who were KIA, Newman, Leininger, Matulik, and Becker, all died within 4 months of each other between November 1943 and March 1944. Not only did they all serve in the 349th Bomb Squadron, but Leininger and Matulik were in the crew of the 'Laden Maiden' when it was shot down killing them both. The timeframe and clear connection between the GIs indicate that they either formed part of the same primary group, or they were linked by a third party. Unfortunately, the service records that might confirm connections between these GIs were destroyed in the 1973 fire at the National Personnel Records Centre, St Louis, MO. The apparent links between the 4 GIs indicates that the dog tags were buried by an individual or individual who knew them all.

As the tags were probably on the 4 GIs were they shot down over enemy territory, then channels must have existed enabling the dog tags to be returned to RAF Thorpe Abbotts. Article 4 of the Geneva 'Convention for the Amelioration of the Condition of the Wounded and Sick in Armies in the Field' states that belligerents 'shall likewise collect and transmit to each other all articles of a personal nature found on the field of battle or on the dead, especially one half of their identity discs, the other half to remain attached to the body' (Geneva Convention 1929, Chapter 1, Article 4 author's emphasis). Throughout the Second World War, there are recorded examples of the 
German military returning dog tags through international channels. On 14 October 1943 a Second Lieutenant, who died when his B-17 Flying Fortress was shot down near Frankfurt, was buried by the Germans with full military honours. When an American War Dead Civilian Investigator opened his grave following hostilities, it was discovered that there were no personal effects on the body. It was customary for the Germans to send on dog tag to the International Red Cross and the other to Berlin (Wood and Stanley 1998, 1370). There also existed a First World War precedence for personal possessions and dog tags to be forwarded to the Red Cross (Whitford and Pollard 2009, 206).

Channels also existed for the reciprocal returning of identification tags by the US military during the war. In the US War Departments Graves Registration Field Manual (FM 10-63), January 1945, it states that the 'identification tag [of an enemy combatant] is then forwarded to the Prisoner of War Information Bureau through channels prescribed by the commanding general of the forces in the field' (War Department 1945, 29). International channels, therefore, existed during the Second World War that would have enabled Newman's, Leininger's, Matulik's, and Becker's dog tags to be returned to the US military following their deaths.

Officially, however, the tags should have been sent to a Quartermaster Graves Registration Service and would have formed part of the individual's file. According to the Quartermaster Museum, VA, the deceased's unit would then be notified of the death of one of their number. As the dog tags could not be returned to the graves of airmen buried in enemy territory, they would have eventually been sent to the Effects Depot in Kansas City and then returned to the family. However, in the case of Newman, Leininger, Matulik, and Becker, their tags were somehow returned to RAF Thorpe Abbotts. Word of mouth evidence reported by the Trustees of the 100th Bomb Group 
Memorial Museum, which has not been verified by the author, record that those dog tags of GIs KIA returned to airfields were sent to the incinerator for destruction. If Newman's, Leininger's, Matulik's, and Becker's dog tags were destined for the incinerator, then someone retrieved them before they were destroyed.

The distribution of the tags indicates that they do not represent a one-off depositional event. Instead, RF05 was one event, RF09, possibly associated with RF12 and RF16, another, and RF10 and RF11, a third. Newman's and Matulik's dog tags (RF05) were excavated in association with a canteen cup and 2 drinks bottles. The burial of these tags, therefore, coincided with the individual or individuals responsible having a drink. At a different time, Becker's tag (RF09) was buried. This event could have happened at the same time as the deposition of Leinginger's (RF16) and Becker's other tag (RF12). The final event was the burial of Bauman's (RF10) and Treanor's (RF11) dog tags, who both survived the war. Before being shipped back to the States, it was possible that these 2 GIs felt the need to leave behind a token of their presence. The proximity of the two tags indicates that the burial occurred during the same event with both Bauman and Treanor present.

Whilst stationed at RAF Thorpe Abbotts, Treanor, who was a keen photographer, recorded many aspects of his deployment. His desire to document the war for posterity is indicative of someone who might want to leave behind evidence of his service. It is also interesting to note that within the 100th Bomb Group Memorial Museum's collection is Treanor's uniform. Part of this donation included a single dog tag on its chain. If the excavated tag had been accidentally lost, one assumes he would have received a replacement. As this does not appear to have been the case, it indicates that Treanor's dog tag was purposefully disposed of when it was no longer required. 
The historical and archaeological evidence implies that the dog tags were purposefully buried besides the static water tank: Newman's, Leininger's, Matulik's, and Becker's following their deaths over enemy territory, and Bauman's and Treanor's at the end of the war. It is hypothesised that grieving comrades deposited the tags of those KIA. This site then became the focus of remembrance and developed into a vernacular memorial as tokens were left in memory of the deceased. Unsanctioned rites of remembrance and commemoration have received little attention in the academic literature on the response of combat units to grief and loss (Rubin 1985, 796). In the next section, the author will examine briefly grief and bereavement in the military and how personal acts of remembrance can assist troops coming to terms with loss.

\section{Discussion}

The study of materiality and material culture has been covered in extensive detail elsewhere (e.g., Arenas 2014; Gosden and Marshall 1999; Hodder 2012; Hurcombe 2007; Knappett 2005; Saunders 2003; Saunders 2012; Schiffer 1999; Tilley 1999). It is also a well established in the field of conflict studies (Pollard 2015, 189-190). This is because the materiality of war represents human experience, including personal tragedy and loss of life (Schofield 2002, 2). Objects owned and created by those caught up in conflict reflect the individual and their experiences (Saunders 2009, 37, 38, 40, 54). Attached to these objects are meanings that can be intensely personal (Schofield 2005, 67): they are a way of knowing oneself (Hoskins 1998, 195). Value can also reside in an artefacts link to a specific person (Rydén 2018, 515). Although the design of US Army Air Force (USAAF) identification tags changed throughout the Second World War, they always recorded the individual's name, serial number, blood type, and religion. These incredibly personal objects were the embodiment of their owner. 
The strategic air campaign brought its own specific difficulty for bereaved comrades back on base: the physical remains of the dead did not always return to base. As the bodies of those KIA were not accessible, there was no location for the grieving to focus their mourning and remembrance (Tarlow 1997, 110). For the bereaved, the absence of a body is the "most stressful loss ... With a clear-cut loss, there is more clarity - a death certificate, mourning rituals, and the opportunity to honor and dispose remains. With ambiguous loss, none of these markers exist' (Boss 2004, 553). In the absence of Becker's, Leininger's, Matulik's, and Newman's remains, dog tags acted in lieu of their bodies. The burial of these objects that personified the dead, offered the bereaved an opportunity to grieve.

During times of conflict, individual's struggle to come to terms with injury, loss, and despair (Saunders 2002, 101). The motivation of soldiers in combat, therefore, relies heavily on their social groupings that are governed by face-to-face relations (Moskos 1970, 135, 144). By living, working and socialising together, units develop a high level of intimacy (Shils and Janowitz 1948, 285). The closeness of the primary group often provides soldiers with their major source of support (Tyler and Gifford 1991, 235). It is this intimacy and solidarity with members of their unit, that influence a soldier's behaviour in combat (Moskos 1970, 135, 144): they are expected to place loyalty above self-preservation (Wong and Gerras 2006, 22). During combat, soldiers not only face the threat of death, or often more frightening, loss of limb, but also the maiming and loss of their comrades (Holmes 2004, 182, 188). The strong social bonds developed within units means that the death of any of its members would have an inevitable emotional toll on the troops.

As soldiers in battle are often 'ill-equipped to respond to their particular kind of loss' (Tarlow 1997, 111), they develop personal coping strategies. One defence 
mechanism, used by troops to help cope with this psychological strain, is to develop a 'shell' of cynicism or indifference (Holmes 2004, 203). Aircrews that served during the Second World War were often reported as being supremely realistic (Stafford-Clark 1948, 15). Despite this, individuals would still suffer grief from the loss of a 'buddy' in their intimate primary group. To aid troops in coming to terms with the sudden, and often violent, death, of a comrade, a focus for their mourning is important (Holmes 2004, 200).

One opportunity to mourn is provided by the burial of the deceased by comrades near to the site of battle. Through organising a funeral, no matter how formal, attempts are made to disguise the randomness of death (Holmes 2004, 201). In active combat zones, the digging of a 'proper' grave was an act accorded to a comrade. Soldiers would rather witness the burial of a close friend than listing them as one of the 'missing' (Wilson 2012, 35, 39). However, in combat situations, the deceased's physical body may not always survive the trauma caused by high explosives (Wilson 2012, 31). It is also possible that in the chaos and confusion of battle, the bodies of the fallen could be left behind. In these scenarios, a 'memorial ceremony' could be organised. Today, these are the principal formal rituals conducted by the US military (Tyler and Gifford 1991, 244). The central component of these ceremonies is the preparation of a visible reminder of the deceased soldier: the 'battlefield cross':

'The helmet and identification tags signify the fallen soldier. The inverted rifle with bayonet signals a time for prayer, a break in the action to pay tribute to our comrade. The combat boots represent the final march of the last battle. The beret (in the case of soldiers from airborne units) reminds us that the soldier has taken part in his final jump' (US Military FM7-21.13 Appendix C Section III C-6).

The 'battlefield cross' allows individuals to come to terms with their loss by providing the unit with a focus for their grief. In addition to the formally organised 
ceremonies, soldiers will also conduct their own self-developed rituals. Within one unit observed by Tyler and Gifford (1991, 245), soldiers arranged that medals and other small personal items were buried with their comrade. Other recorded rituals include units gathering to polish the boots or washing the bloody gear of the deceased. One of the most common reactions to the loss of a comrade is the consumption of alcohol; some young soldiers find destroying a bar particularly therapeutic (Tyler and Gifford 1991, 245).

Although a unit will quickly replace a soldier KIA to ensure they remain combat ready, the loss would have emotional repercussions. Despite assurances from veterans that the death of a comrade was just part of war, soldiers would grieve over the loss (Rubin 1985, 796). One way to deal with grief is through the spontaneous construction of a vernacular memorial. These personal mourning rites bring individuals together in shared grief that is directed towards a physical object. Following the sudden and violent death of an individual in a traffic accident, 'roadside memorials' often form an important part of the mourning process of the bereaved (Nešporová and Stahl 2014, 29). Often constructed by friends of the deceased shortly after the death, these 'temporary' memorials create a space where the bereaved can communicate with the dead (Klaassens, Groote and Huigen 2009, 187). Despite being constructed at the site of death, these vernacular memorials are an important analogy for understanding what occurred at RAF Thorpe Abbotts.

At the base of roadside memorials, family members and friends of the deceased often leave small tokens (Nešporová and Stahl 2014, 26). These objects take many forms, but often include items treasured by the dead individual, crosses, flowers and other traditional symbols of commemoration (e.g., Collins and Opie 2010, 109; Klaassens, Groote and Huigen 2009, 192; Kennerly 2002, 235; and Clark and 
Franzmaan 2006, 580). The deposition of these artefacts are attempts by the friends and family to continue a 'relationship' with the dead (Jorgensen-Earp and Lanzilotti 1998, 162). On the Falkland Islands, small personal memorials to the fallen of the Falklands War have been erected. These often take the form of "wooden crossed and offerings that include wooden plaques bearing inscriptions and regimental badges and buttons' (Pollard 2015, 182). As of May 25, 2012, Dan Lamothe’s blog entry, 'On Memorial Day weekend, a look at war-zone tributes', posted on the Marine Times BattleRattle website, contained photographs of 'challenge coins' left in remembrance at a memorial to US Marines at Forward Operating Base Zeebrugge, Afghanistan. This can help those grieving by preserving the memory of the deceased (Collins and Opie 2010, 109). Spontaneously constructing a site of commemoration can provide the bereaved with a mechanism to deal with their sudden loss (Doss 2006, 298). The construction of a memorial also publicly demonstrates that the bereaved have not forgotten the deceased (Klaassens, Groote and Huigen 2009, 196). Comrades of Newman, Leininger, Matulik, and Becker might have left coins besides the static water tank in remembrance of the dead.

In addition to the commemorative tokens excavated from the trench, Newman's and Matulik's dog tags were also found in association with a canteen cup and drinks bottles. It is common at roadside memorials to find artefacts associated with alcohol. Empty beer cans, glasses and the deceased's favourite branded alcohol have all been recorded have all been recorded at commemorative sites in Australia, the USA, UK and New Zealand (Klaassens, Groote and Huigen 2009, 192). The presence of alcoholic beverages at memorials could indicate that the bereaved gathered for a wake (Clark and Cheshire 2004, 210). Friends and family of the deceased often report visiting the sites to have a drink (Klaassens, Groote and Huigen 2009, 198). The canteen cup and drinks 
bottles could be evidence of the bereaved 'toasting' the memory of Newman and Matulik as they buried the tags.

\section{Conclusion}

In their repeated and continued exposure to death and injury, troops often develop a shell of cynicism or indifference towards the threat. Without coping strategies, the continual emotional strain of combat would eventually make it impossible for them to continue functioning. No matter the individual's response, the fear of being killed or wounded, and being forced to watch comrades suffering and dying, would have a psychological impact (Holmes 2004, 203). When faced with loss, it is inevitable that a soldier will grieve to a greater of lesser extent (Durham 1996, 13). In order to address the negative impact of grief on combat effectiveness, the US military organises official ceremonies. There provide the bereaved the opportunity to honour their fallen and to being the process of individual and collective healing (Stice 2008, 10, 12, 17).

In addition to 'official' acts of mourning, primary groups within the military develop their own rituals to deal with the loss of a comrade (Hope 2017, 12). These rites help to reinforce the collective identity of the unit (Reimers 1999, 148). Whilst excavating the 100th Bomb Group's Communal Site No. 1 at RAF Thorpe Abbotts, one response to grief was uncovered. Tucked away on the bank of the static water tank, a comrade or comrades of Sgt Max Newman, Lt Marvin Leininger, S/Sgt Nicholas Matulik and S/Sgt Donald Becker buried their dog tags in an act of remembrance. When the bereaved returned to the site, tokens were left to commemorate the dead. Why this location was chosen for a site of vernacular memorialisation is uncertain. One explanation might be that the static water tank was a place for off-duty socialising, where the dead were discussed and remembered. The acts of commemoration and remembrance that occurred at this location helped to maintain and reinforce the identity 
of primary group (King 2010, 19). They also allowed the GIs of the 100th Bomb Group to grieve (Clark and Franzmaan 2006, 593).

\section{References}

2nd Air Division Memorial Library Microfilm B01418 (Hethel).

Arenas, J. 2014. "Changing Perspectives: the Archaeology of Memory and Material Culture." Archaeological Review from Cambridge 29 (2): 69-87.

Balicki, J. 2011. "Watch-Fires of a Hundred Circling Camps: Theoretical and Practical Approaches to Investigating Civil War Camps.” In Historical Archaeology of Military Sites: Method and Topic, edited by Clarence Geier, Lawrence Babits, Douglas Scott, and David Orr, 57-73. College Station: Texas A\&M University Press.

Barnes, J. 2018. "Nails, tacks, and hinges: the Archaeology of Camp Monticello, a World War II Prisoner of War Camp.” Southeastern Archaeology 37 (3): 169189. doi: https://doi.org/10.1080/0734578X.2017.1420840.

Black, J. 2004. “"Thanks for the Memory': War Memorials, Spectatorship and the Trajectories of Commemoration 1919-2001." In Matters of Conflict: Material Culture, Memory and the First World War, edited by Nicholas Saunders, 134148. Abingdon: Routledge.

Boss, P. 2004. “Ambiguous Loss Research, Theory, and Practice: Reflections After

9/11." Journal of Marriage and Family 66 (3): 551-566. doi:

https://doi.org/10.1111/j.0022-2445.2004.00037.x.

Carr, G. 2012. "Examining the Memorialscape of Occupation and Liberation: a Case Study from the Channel Islands." International Journal of Heritage Studies 18 (2): 174-193. doi: https://doi.org/10.1080/13527258.2011.606330.

Carr, G. 2018. "The Small Things of Life and Death: an Exploration of Value and Meaning in the Material Culture of Nazi Camps." International Journal of Historical Archaeology 22: 531-552. doi: https://doi.org/10.1007/s10761-0170435-0.

Carr, G., and Mytum, H. 2012. "The Importance of Creativity Behind Barbed Wire:

Setting a Research Agenda." In Cultural Heritage and Prisoners of War:

Creativity Behind Barbed Wire, edited by Gilly Carr and Harold Mytum, 1-15. New York: Routledge. 
Clark, J., and A. Cheshire. 2004. "RIP by the Roadside: a Comparative Study of Roadside Memorials in New South Wales, Australia, and Texas, United States.” Omega 48 (3): 203-222. doi: https://doi.org/10.2190/3RED-6H7D-PNNCURT7.

Clark, J., and Franzmann, M. 2006. "Authority from Grief, Presence and Place in the Making of Roadside Memorials.” Death Studies 30 (6): 579-599. doi: https://doi.org/10.1080/07481180600742574.

Collins, C., and A. Opie. 2010. "When Places have Agency: Roadside Shrines as Traumascapes." Journal of Media and Cultural Studies 24 (1): 107-118. doi: https://doi.org/10.1080/10304310903419559.

Cornelison, J. 2000. “The Archaeology of Retreat: Systematic Metal Detector Survey and Information Analysis at the Battle of Chickamauga, September 1863.” In Archaeological Perspectives on the American Civil War, edited by Clarence Geier and Stephen Potter, 289-304. Gainesville: University Press of Florida.

Doss, E. 2006. "Spontaneous Memorials and Contemporary Modes of Mourning in America." Material Religion 2 (3): 294-318. doi: https://doi.org/10.1080/17432200.2006.11423053.

Durham, M. 1996. The Grief Impact on Soldier Morale during Extended Deployments. Pennsylvania: US Army War College.

Ferguson, N. 2013. "Biting the Bullet: the Role of Hobbyist Metal Detecting within Battlefield Archaeology." Internet Archaeology 33 (3). doi https://doi.org/10.11141/ia.33.3.

Freeman, R. 1997. "Forward”. In Century Bombers: The Story of the Bloody Hundredth by R. Le Strange. Thorpe Abbots: 100th Bomb Group Memorial Museum.

Geneva Convention for the Amelioration of the Condition of the Wounded and Sick in Armies in the Field, 27 July 1929.

Gosden, C., and Marshall, Y. 1999. "The Cultural Biography of Objects.” World Archaeology 31 (2): 169-178. doi: https://doi.org/10.1080/00438243.1999.9980439.

Hodder, I. 2012. Entangled: an Archaeology of the Relationships between Humans and Things. Chichester: Wiley-Blackwell.

Holmes, R. 2004. Acts of War: The Behaviour of Men in Battle. London: Cassell. 
Hope, V. 2017. ““'Dulce et decorum est pro patria mori”: The Practical and Symbolic Treatment of the Roman War Dead." Mortality 23 (1): 35-49. doi: https://doi.org/10.1080/13576275.2017.1282943.

Hoskins, J. 1998. Biographical Objects: How Things Tell the Stories of People's Lives. London: Routledge.

Hurcombe, L. 2007. Archaeological Artefacts as Material Culture. Abingdon:

Routledge.

Jorgensen-Earp, C., and L. Lanzilotti. 1998. "Public Memory and Private Grief: the Construction of Shrines at the Sites of Public Tragedy." Quarterly Journal of Speech 84 (2): 150-170. doi: https://doi.org/10.1080/00335639809384211.

Joy, J. 2002. "Biography of a Medal: People and the Things they Value”. In Material Culture: the Archaeology of Twentieth Century Conflict, edited by John Schofield, William Johnson and Colleen Beck, 132-142. Oxon: Routledge. Keating, M. 2012. “The Poppy and the Harp: Contested Meanings at 'The Oratory', Dun Laoghaire, Ireland." In Beyond the Dead Horizon: Studies in Modern Conflict Archaeology, edited by Nicholas Saunders, 14-28. Oxford: Oxbow.

Kennerly, R. 2002. "Getting Messy: In the Field and at the Crossroads with Roadside Shrines." Text and Performance Quarterly 22 (4): 229-260. doi: https://doi.org/10.1080/10462930208616172.

King, A. 2010. "The Afghan War and Postmodern Memory: Commemoration and the Dead of Helmand." The British Journal of Sociology 61 (1): 1-25. Doi: https://doi.org/10.1111/j.1468-4446.2009.01299.x.

Klaassens, M., P. Groote, and P. Huigen. 2009. "Roadside Memorials from a Geographical Perspective.” Mortality 14 (2): 187-201. doi: https://doi.org/10.1080/13576270902808068.

Knappett, C. 2005. Thinking Through Material Culture: an Interdisciplinary Perspective. Philadelphia: University of Pennsylvania Press.

Le Strange, R. 1997. Century Bombers: The Story of the Bloody Hundredth. Thorpe Abbots: 100th Bomb Group Memorial Museum.

Moshenska, G. 2006. "Scales of Memory in the Archaeology of the Second World War." Papers from the Institute of Archaeology 17: 58-68. doi: http://doi.org/10.5334/pia.269. 
Moshenska, G. 2009. "Resonant Materiality and Violent Remembering: Archaeology, Memory and Bombing." International Journal of Heritage Studies 15 (1): 4456. doi: https://doi.org/10.1080/13527250902746062.

Moskos, C. 1970. The American Enlisted Man: The Rank and File in Today's Military. New York: Russell Sage Foundation.

Myers, A. 2008. "Between Memory and Materiality: an Archaeological Approach to Studying the Nazi Concertation Camps." Journal of Conflict Archaeology 4 (12): 231-245. doi: https://doi.org/10.1163/157407808X382827.

Nešporová, O., and I. Stahl. 2014. "Roadside Memorials in the Czech Republic and Romania: Memory Versus Religion in Two European Post-Communist Countries." Mortality 19 (1): 22-40. doi: https://doi.org/10.1080/13576275.2013.870543.

Nilsson, J. 1946. The Story of the Century. Beverly Hills: John Nilsson.

Pollard, T. 2009. "The Rust of Time: Metal Detecting and Battlefield Archaeology.” In Metal Detecting and Archaeology, edited by Suzie Thomas and Peter Stone, 181-202. Woodbridge: Boydell Press.

Pollard, T. 2011. "Dissecting Seventeenth- and Eighteenth- Century Battlefields. Two Case Studies from the Jacobite Rebellions in Scotland." In Historical Archaeology of Military Sites: Method and Topic, edited by Clarence Geier, Lawrence Babits, Douglas Scott, and David Orr, 99-111. College Station: Texas A\&M University Press.

Pollard, T. 2015. "Islands of No Return: Memory, Materiality and the Falklands War." In Heritage and Memory of War: Responses from Small Islands, edited by Gilly Carr and Keir Reeves, 177-193. Oxon: Routledge.

Reimers, E. 1999. "Death and Identity Graves and Funerals as Cultural Communication.” Mortality 4 (2): 147-166. doi: https://doi.org/10.1080/713685976.

Renshaw, L. 2016. Exhuming Loss: Memory, Materiality, and Mass Graves of the Spanish Civil War. Oxon: Routledge.

Rubin, N. 1985. “Unofficial Memorial Rites in an Army Unit.” Social Forces 63 (3): 795-809. doi: https://doi.org/10.1093/sf/63.3.795.

Rydén, J. 2018. "When Bereaved of Everything: Objects from the Concentration Camp of Ravensbrück as Expressions of Resistance, Memory, and Identity." 
International Journal of Historical Archaeology 22: 511-531. doi:

https://doi.org/10.1007/s10761-017-0433-2.

Saunders, N. 2002. "Excavating Memories: Archaeology and the Great War, 1912001." Antiquity 76 (291): 101-108. doi: https://doi.org/10.1017/S0003598X00089857.

Saunders, N. 2003. Trench Art: Materialities and Memories of War. Oxon: Berg.

Saunders, N. 2009. "People in Objects: Individuality and the Quotidian in the Material Culture of War." In The Materiality of Individuality: Archaeological Studies of Individual Lives, edited by Carolyn White, 37-55. New York: Springer.

Saunders, N. 2012. "Introduction: Engaging the Materialities of Twentieth and TwentyFirst Century Conflict." In Beyond the Dead Horizon: Studies in Modern Conflict Archaeology, edited by Nicholas Saunders, x-xiv. Oxford: Oxbow.

Schiffer, M. 1999. The Material Life of Human Beings: Artifacts, Behaviour, and Communication. London: Routledge.

Schofield, J., Johnson, W., and Beck, C. 2002. "Introduction: Matériel Culture in the Modern World." In Matériel Culture: the Archaeology of the Twentieth Century Conflict, edited by John Schofield, William Johnson, and Colleen Beck, 1-8. Oxon: Routledge.

Schofield, J. 2005. Combat Archaeology: Material Culture and Modern Conflict. London: Duckworth.

Shils, E., and M. Janowitz. 1948. "Cohesion and Disintegration in the Wehrmacht in World War II." The Public Opinion Quarterly 12 (2): 280-315. url: http://www.jstor.org/stable/2745268.

Sledge, M. 2005. Soldier Dead: How We Recover, Identify, Bury, and Honor Our Military Fallen. New York: Colombia University Press.

Stafford-Clark, D. 1948. "Morale and Flying Experience: Results of a Wartime Study." Journal of Mental Science 95 (398): 10-50. doi: https://doi.org/10.1192/bjp.95.398.10.

Stice, K. 2008. Post-Deployment Memorial Ceremony: a Vital Link. Pennsylvania: US Army War College.

Stephens, J. 2007. "Memory, Commemoration and the Meaning of a Suburban War Memorial." Journal of Material Culture 12 (3): 241-261. doi: https://doi.org/10.1177/1359183507081893. 
Stone, M. 2004. “A Memory in Ruins?” Public Archaeology 3 (3): 131-144. doi: https://doi.org/10.1179/pua.2004.3.3.131.

Tarlow, S. 1997. “An Archaeology of Remembering: Death, Bereavement and the First World War." Cambridge Archaeological Journal 7 (1): 105-121. doi: https://doi.org/10.1017/S0959774300001499.

Tilley, C. 1999. Metaphor and Material Culture. Oxford: Blackwell Publishers.

Trigg, J. 2007. "Memory and Memorial: A Study of Official and Military Commemoration of the Dead, and Family and Community Memory in Essex and East London." Journal of Conflict Archaeology 3 (1): 295-315. doi: https://doi.org/10.1163/157407807X257476.

Tyler, M., and R. Gifford. 1991. "Fatal Training Accidents: The Military Unit as a Recovery Context." Journal of Traumatic Stress 4 (2): 233-249. doi: https://doi.org/10.1002/jts.2490040207.

War Department. 1945. FM 10-63: Graves Registration January 1945. Washington: War Department.

Whitford, T., and T. Pollard. 2009. "For Duty Done: A WWI Military Medallion Recovered from the Mass Grave a Site at Fromelles, Northern France." Journal of Conflict Archaeology 5 (1): 201-229. doi: https://doi.org/10.1163/157407709X12634580640533.

Wilson, R. 2012. "The Burial of the Dead: the British Army on the Western Front, 1914-18." War and Society 31 (1): 22-41. doi: https://doi.org/10.1179/204243411X13201386799136.

Wong, L., and S. Gerras. 2006. CU@ the FOB: How the Forward Operating Base if Changing the Life of Combat Soldiers. Pennsylvania: Strategic Studies Institute.

Wood, W., and L. Stanley. 1989. "Recovery and Identification of World War II Dead: American Graves Registration Activities in Europe." Journal of Forensic Sciences 34 (6): 1365-1373. doi: https://doi.org/10.1520/JFS12778J.

Figure 1. Map showing the location of RAF Thorpe Abbotts in the East of England.

Figure 2. 1946 site plan of RAF Thorpe Abbotts. The location of the water tank is highlighted by the black square (C RAF Museum). 
Figure 3. Cross section and plan of the Water Tank trench at RAF Thorpe Abbotts.

Figure 4. Photograph of the seven dog tags excavated from the Water Tank trench. First row: S/Sgt Nicholas Matulik (RF5) and Sgt Max Newman (RF5); second row: S/Sgt Donald Becker (RF9) and S/Sgt Donald Becker (RF12); third row: Cpl Karl Treanor (RF11) and Lt Marvin Leininger (RF16); fourth row: Lt Jack Bauman (RF10). 